\title{
Revolutionary Tourism: Research on the New Path of Ideological - Political Education
}

\author{
Fanrong Meng* \\ College of Marxism, Jiangxi Normal University, Nanchang, Jiangxi 330022, China.
}

\begin{abstract}
China has abundant revolutionary tourism resources so the development of revolutionary tourism has great potential. General Secretary once compared the history of the party to the best textbook for the people. It is true that in order to enhance the affinity of ideological - political education, the development of ideological - political education through revolutionary tourism can not only allow tourists to enjoy sightseeing and leisure, but also cultivate their national awareness and ethnicity feelings. Revolutionary tourism and ideological-political education are consistent in the value system. Based on the analysis of the elements of the ideological - political education process, there are also some problems in integrating revolutionary tourism into ideological - political education. Therefore, exploring the realization path of revolutionary tourism in ideological - political education is of great importance.
\end{abstract}

Keywords: Revolutionary Tourism; Ideological - Political Education; Educational Value

\section{Introduction}

Revolutionary tourism mainly refers to tourism activities that people go to revolutionary and historically memorable tourist destinations to reminisce about the past, know the red culture, and receive the traditional education of patriotic revolution while sightseeing, leisure, and physical and mental pleasure. Facing different cultural shocks worldwide, it is necessary to continuously strengthen citizens' patriotism and ideological - political education. It is not only the need to promote the core values of socialism, but also the need to promote the free and comprehensive development of people. General Secretary proposed to "enhance the affinity and pertinence of ideological - political education ${ }^{[1]}$." As a new carrier to promote the spirit of patriotism, revolutionary tourism should be widely used in ideological - political education. Revolutionary tourism should be regarded as a vital way to disseminate patriotic feelings, promote national identity and civic personality education. However, in the process of ideological - political education, revolutionary tourism has problems such as weak subject consciousness, low enthusiasm of the educated, single educational method, and redundant educational environment. Therefore, how to make better use of the value of revolutionary tourism in ideological - political education and to explore the realization path of revolutionary tourism in ideological - political education is particularly important.

\section{Development status of revolutionary tourism}

Revolutionary tourism can not only improve economic efficiency, it is also an important ideological and political lesson. It covers history, pedagogy, political science, tourism and other disciplines, and has a strong spiritual and cultural background. Visiting the red tourist destination not only enriches the classroom form of ideological - political education, allows tourists to feel the patriotism of revolutionary martyrs, but also enhances the sense of mission and responsibility of every tourist in a subtle way.

First of all, the red tourist areas are located in cities all over the country, and it is feasible to integrate ideological - political education in space. There are 12 key red tourist attractions in China. These tourist areas are very comprehensive. They are not only diverse in image and theme, but also very popular among tourist destinations involving 112 scenic spots which are divided into three categories. Among them, the active development areas involve 12 urban areas such as Beijing, Shanghai and Tianjin, with a total of 30 red tourist attractions. The key development areas include 24 red tourist attractions in Jiangsu Province, Harbin, Taiyuan and other provinces and cities. The potential development zone includes a total of 46 red tourist attractions in cities like Lu'an City. The spiritual value contained in these attractions cannot be forgotten through generations. Secondly, in the first half of 2019, national revolutionary tourism trips reached 268 million, a year-on-year growth rate of $4.13 \%$, accounting for $5.90 \%$ of the country's total domestic tourism revenue during the same period.

\section{The effect of revolutionary tourism on ideological - political education}

In reality, the cultural heritage of revolutionary tourism and ideological - political education are closely linked. Revolutionary

Copyright (C) 2020 Fanrong Meng

doi: 10.18282/1-e.v9i4.1742

This is an open-access article distributed under the terms of the Creative Commons Attribution Non-Commercial License (http://creativecommons.org/licenses/by-nc/4.0/), which permits unrestricted non-commercial use, distribution, and reproduction in any medium, provided the original work is properly cited. 
tourism not only enhances the affinity of ideological - political education, but also allows more specific forms of cultural inheritance. The development of revolutionary tourism is good to maximize the effects of ideological - political education.

\subsection{Revolutionary tourism provides a new carrier for ideological - political education}

Cultural undertakings are the main cultural carrier of ideological - political education such as radio and television, libraries, museums, etc., and its forms are diverse. Revolutionary tourism provides a rich carrier for ideological - political education through paintings, calligraphy, old objects, plenty of photos, diagrams, and 3D models. The smart red tourist attraction reproduces the heroic posture of the soldiers with advanced technology, through deeds of the heroes and martyrs that influence people's values and morals, and also enable people to learn scientific and cultural knowledge and professional skills, thereby enhancing people's thinking style and aesthetic ability. This influence is subtle and has a certain degree of permeability. Educational objects often to do something without studying it first after one has become accustomed to it.

\subsection{Revolutionary tourism is consistent with the leading value of ideological - political education}

Revolutionary tourism means that people go to revolutionary tourism destinations to receive traditional education of patriotism, which has obvious ideological and moral value guidance. The content of ideological - political education is based on the socialist core value system and socialist core values, and the purpose is to improve citizens' ideological and moral qualities and scientific and cultural qualities. "The leading value of ideological - political education is political value and spiritual value ${ }^{[2]}$." Revolutionary tourism resources also have certain political and ideological education values. The revolutionary tourism resources contain the historical background and national sentiments of the Chinese people who have worked hard under the leadership of the Communist Party of China, and countless people with lofty ideals have overcome difficulties, resisted oppression and aggression, and saved the nation from peril. Its political orientation is to adhere to the leadership of the Communist Party of China, is in line with the direction of socialism, and is conducive to people's political awareness, so as to shoulder the responsibility of the times to realize the great rejuvenation of the Chinese nation. China should uphold the leadership of Marxism in ideological work, letting the people know more about the great journey of the $\mathrm{CPC}$ leading the people to victory in the revolution. At present, socialism with Chinese characteristics has entered a new era, and our revolutionary tourism resources have displayed a national vision in a special form in terms of political orientation. The ideological value of revolutionary tourism resources is mainly reflected in the spiritual power it embodies. The Red Boat Spirit, Jinggangshan Spirit, Xibaipo Spirit, etc. continue to guide young people to firmly establish a correct view of the country, historical view and national view.

\subsection{Revolutionary tourism can enrich the content of ideological - political education}

The two are interlinked in content. On the one hand, revolutionary tourism is actually a process of ideological - political education. It is a process of "educators and educated people participating and interacting together ${ }^{[3] "}$. On the other hand, revolutionary tourism is an innovative form of ideological - political education, which can more stimulate the interest of education subjects and be more practical. The elements of Chinese culture, historical sentiments, and the struggle of the party embodied in revolutionary tourism provide materials for ideological - political education. Revolutionary tourism integrates sightseeing and education, and shows the revolutionary spirit in a way that people like to hear and see. While meeting people's needs for a better life, it also makes patriotic education more attractive. Under normal circumstances, boring classroom education tends to make students weariness, and tourism transforms abstract "crawling" education into "experiential" education, which helps people form a good political outlook.

\section{Problems of revolutionary tourism in the process of incorporating into ideological - political education}

The basic elements of the ideological - political education process are the educator, the educated, the educational mediator, and the educational circle. The process of ideological - political education is a benign system, and only the coordinated development of these elements can achieve good results in ideological - political education activities. Then the problems in these aspects in the process of integrating revolutionary tourism into ideological - political education should not be underestimated.

\subsection{The educator's subjective consciousness is not strong}

In revolutionary tourism activities, educators broadly refer to local governments and tourism practitioners who advocate revolutionary tourism. In the process of developing revolutionary tourism, the local government overemphasized the "check-in system" and regarded it as a task to roughly complete, forcibly allowing some colleges and universities, government agencies and enterprises to visit designated places, or some colleges and universities have a "passion for patriotism" in cultivating students. It's the attitude of the student. In a narrow sense, educators are guided tours, individuals or groups that have a purposeful and planned educational influence. The tour guide should be familiar with the general situation of the tourist destination, including the natural scenery and humanistic characteristics of the tourist destination, in order to better affect every tourist (educated) with the revolutionary feelings of the red tourist destination. Two reasons caused the problem in the process. The objective reason is the scarcity of professional talents, and the subjective reason is that the tour guides lack professional knowledge, focus on play, ignore the historical background of the red tourist destination, and recite the guide word template during the explanation. Tour guides cannot adapt to the time and place, and the interaction with tourists is not strong.

\subsection{The educated are not motivated}

Revolutionary tourism is to cultivate the correct national consciousness and national sentiment while people visit the revolutionary memorial sites, but the resistance shown by many educated people is not in line with the original vision of revolutionary tourism. The object of education is the direct manifestation of the effect of ideological - political education. Most of the educated involved in the revolutionary tourism are cadres of party and government organs, grassroots party organizations 
in colleges and universities, and a large number of student groups. Some educated persons hold the one-sided feeling of "I know that I am patriotic" in joining patriotism and nationalism education activities, and do not actively participate in ideological political education activities arranged by units or higher-level party organizations. "When I went to visit the revolutionary tourist destination, I felt like wasting time and learning nothing." Under the guise of being an advanced party member, participants are just in order to complete the task and formalism is serious. However, the majority of college students are born in the 90s, unfamiliar to the revolutionary era. They have not experienced that difficult era and cannot wholly understand the revolutionary spirit. Some students said that if there is no teacher's guidance, they will not take the initiative to learn revolutionary culture. Of course, there is also limited ability of educated persons to accept knowledge and ability to participate in the ideological - political education of revolutionary tourism.

\subsection{Inherent education content}

In the teaching process, educators have used the same PPT for several years, and they do not keep pace with the times, and the target of education is not specific. And only with certain methods can the excellent revolutionary cultural traditions and lofty national feelings be better transmitted to the educated. At present, the widespread patriotic education method is still classroom teaching. This traditional "cracking duck" teaching is difficult to arouse the interest of the educated and cannot achieve good interactive effects. How to tell the revolutionary story well to demonstrate the influence of the revolutionary brand requires educators to take many forms. Telling the revolutionary story well is not only limited to the classroom. There are also many places where practical teaching is implemented. For example, many universities and institutions in Nanchang, Jiangxi Province will organize visits to the August 1st Uprising Memorial Hall, but many organizations just go to pull a banner and take a few photos.

\subsection{Complicated education environment}

"People create the environment, and the environment also creates people." First of all, the homogeneity of scenic spots is becoming more and more severe. The infrastructure construction of revolutionary tourist spots also needs to be improved. Besides, the peripheral environment of some scenic spots does not fit the cultural atmosphere, such as the commercial street next to the August 1st Nanchang Uprising Memorial Hall, which has serious commercial atmosphere. The second is the social environment. 2019 is the 70th anniversary of the founding of the People's Republic of China. National sentiments and pride are like the spring breeze hitting the streets and alleys. Flags can be seen fluttering in the wind on the streets. Compared with previous years, the festive atmosphere is stronger. Political education lacks such an external environment. The impact of the environment on people is subtle but can moisturize things silently. Therefore, government departments should pay more attention to the macro circumstance and build cultural brands. Finally, there is a serious profit-seeking phenomenon in scenic spots. Revolutionary tourist attractions are divided into two categories, in which one is public welfare and the other is non-public welfare. The six elements of tourism are food, accommodation, transportation, travel, entertainment, and shopping. Non-profit scenic spots continue to increase prices for food, accommodation, and tickets, causing some people to dare not go, rather than not want to go.

\section{The innovative path of revolutionary tourism ideological - political education}

\subsection{Subject consciousness: make ideological - political education more "quality"}

The subjectivity of ideological - political education is the interaction and creativity in the process of educators exerting educational influence on the educated. Educators need to be able to take the initiative to implement teaching based on reality, character and moral status of the educational object and guide the educated to form the ideological and moral qualities required by society. In the process of choosing revolutionary tourism practice teaching, colleges and universities should solicit more opinions from students, and really arrange for students to go where they want and learn what they want to learn. As a tour guide, you must first have professional knowledge to better educate others, and then you must have patriotism to make the tour guide more appealing. Therefore, scenic spots and colleges and universities can collaborate to train high-quality tour guides and hold regular training courses to achieve good results in the ideological - political education of revolutionary tourism.

\subsection{Ideological and political classroom: make ideological - political education more "live"}

Ideological and political theory courses are compulsory courses for every college student. First, revolutionary tourism should be combined with the public compulsory courses that college students are studying, and revolutionary tourism should be integrated into the ideological and political classroom, such as "Modern History Outline", "Ideological and Moral Cultivation and Legal Foundation" and other courses. This is also a shortcut to tell the red stories and model stories well in the ideological and moral classes of elementary and middle schools. Secondly, in carrying out ideological - political education, colleges and universities should organize students to study in the revolutionary tourist destinations with distinctive characteristics. They can also invite some Red Army spiritual propaganda groups to the school to hold seminars and tell students the revolutionary story. Finally, revolutionary tourism resources can be used to hold some essay, calligraphy, singing red songs, and speech contests, with students as the main body, flip the classroom, arouse students' enthusiasm, and cultivate students' sense of competition. On November 3, 2019, the finals of the 9th National College Student Revolutionary Tourism Creative Planning Competition was held in Jinzhai, Anhui. 30 provinces, 236 schools, and 630 teams participated in this competition, of which 29 were shortlisted in the finals. The teams are based on the inheritance of culture, and integrate the ideological - political education of college students with the professional education of tourism. One of the goals of this competition is to inherit the revolutionary culture, create an ideological and political brand project for college students, and continue to develop MOOC products.

\subsection{Traditional experience: make ideological - political education more "fans"}

Revolutionary tourist attractions should be more attractive when developing tourist projects, so that tourists can continue 
to learn while playing. All units should strive to reach a cooperative relationship with scenic spots, organize research tours on a regular basis, and design experiential tourism projects in traditional scenic spots, such as reminiscing red rice, re-walking the Red Army Road, and singing Red Army songs. On November 11, 2019, Hunan Province held the Revolutionary Tourism Cultural Square Dance. 14 prefectures and cities participated in the event. In this event, the broad masses of people actively participated, which also drove the whole body fitness exercise, played a very good linkage effect and passed on the revolutionary spirit through dance.

\subsection{Ideals and beliefs: make ideological - political education more "powerful"}

Communists are the vanguards of the Chinese people. Every member of the party and government agencies should have a correct attitude and earnest study when receiving ideological - political education on revolutionary tourism. The power of role models is infinite. Moreover, revolutionary tourism can be combined with the theme of the "Chinese dream", allowing tourists to understand that the great rejuvenation of the Chinese nation is hard-won, and the journey of the Chinese revolution has been bumpy. In 2019, the whole party will carry out nationwide education on the theme of "Don't forget the original heart, keep in mind the mission", continuing to educate party members and comrades on the revolutionary culture, cultivate the national spirit of patriotism, and keep the original aspiration in order to be able to undertake the mission of the great rejuvenation of the Chinese nation. Party members and cadres should go to the revolutionary tourist destinations to learn the quality of serving the people of the revolutionary ancestors, and the spiritual perseverance of hard work, so that revolutionary tourism will be more effective when it is integrated into ideological - political education.

\subsection{Create atmosphere: make ideological - political education more "hot"}

The integration of revolutionary tourism into ideological - political education requires a good external environment. The government should take the initiative to carry out education and publicity of revolutionary tourism. How to effectively develop the economic and political functions of revolutionary tourism requires the improvement of infrastructure and the construction of revolutionary scenic spots with full enthusiasm. At the same time, we will improve the implementation methods of various cultural tourism, optimize the surrounding environment of the scenic area, so as to boost the local economy and play a good revolutionary cultural card. Schools should also vigorously promote revolutionary culture, use media network technology, and set up more cultural and tourism projects in rolling publicity boards. Schools can also promote revolutionary tourism in long term through broadcasts, magazines, etc., to make the red atmosphere stronger, and to promote the various aspects of revolutionary tourism. Political and spiritual value is brought to the campus in various forms, and schools actively create a learning revolutionary cultural atmosphere. Scenic spots should also continue to expand the influence through social resources such as WeChat official accounts, and attract all kinds of subjects to travel.

\subsection{Institutional mechanism: make the integration of the two more "standard"}

Innovating systems and mechanisms can further expand the growth of the revolutionary tourism market. General Secretary mentioned in the Fourth Plenary Session of the 19th Central Committee: "We must improve the system and mechanism for the integration and development of culture and tourism ${ }^{[4]}$." It is necessary to organically integrate revolutionary culture and tourism to promote each other and develop together. The first is to innovate financial system, expand the scope of revolutionary tourism investment entities, support the establishment of revolutionary tourism investment and financing platforms in revolutionary tourism areas, establish red cultural tourism investment funds, guide and drive financial capital and social capital to participate in the development of revolutionary tourism and develop key revolutionary tourism projects; the second is to innovate market management mechanism, strengthen the main body of revolutionary tourism operation, support the cultivation of a group of leading revolutionary tourism enterprises; thirdly, innovate the talent training mechanism, focus on cultivating a group of outstanding revolutionary story interpreters, revolutionary tourism product designers, revolutionary tourist attractions management personnel and revolutionary tourism volunteer team. Continuously improve the competitiveness of the revolutionary tourism market by promoting the integration and innovation of investment entities, business entities and service entities.

\section{Conclusion}

In recent years, revolutionary tourism has continued to rise and develop. On the basis of inheriting the excellent Chinese cultural traditions, revolutionary tourism better combines the economic and social functions of tourism culture. Revolutionary tourism provides a new carrier for ideological - political education. Through analyzing the role of revolutionary tourism in ideological political education and the problems existing in the development process, based on reality, starting from the educational subject, educational object, educational mediator, and educational circle, combining the characteristics of revolutionary tourism, it proposes measures such as enhancing subject consciousness, stimulating the vitality of the subject, strengthening ideals and convictions, invigorating ideological and political classrooms, providing a new path for the integration of revolutionary tourism into ideological - political education, continuously innovating cultural and tourism integration systems and mechanisms, and opening up new opportunities for the revolutionary tourism markets.

\section{References}

[1].Putting Ideological and Political Work Through the Whole Process of Education and Teaching Create a New Situation for the Development of Higher Education [N].People's Daily, 2016-12-09; (1).

[2].Li Heliang. (2015).A New Explanation of the Relationship between Social Value and Personal Value of Ideological and Political Education[J].Teaching and Research, (5): 84-90.

[3] Duan Weixiao.(2014). A Probe into the "School-Teacher-Student" Interactive Model of Ideological - Political Education in 


\title{
Discussion on Oboe Teaching and Cultivation of Comprehensive Quality
}

\author{
Yang Zhang* \\ H.S. Skovoroda Kharkiv National Pedagogical University, Kharkiv, Ukraine
}

\begin{abstract}
With the continuous deepening of education reform, more demands are placed on the current teaching. Oboe teaching needs to adapt to the pace of education reform and make certain changes to teaching ideas and methods. While doing basic teaching well, it is necessary to improve the comprehensive quality of students, so that students can meet the needs of social development. Therefore, in teaching, teachers need to innovate existing teaching methods, focus on cultivating students' comprehensive qualities, improve the overall quality of teaching, and ensure that students can achieve comprehensive development.
\end{abstract}

Keywords: Oboe Teaching; Training Comprehensive Quality; Training Methods

In recent years, with the continuous popularization of symphony, people's understanding of music has been continuously improved, and a music learning trend has gradually formed in society. The oboe has been around for hundreds of years, but at present, my country is in the embryonic stage of development. Most people do not understand the oboe, and there is a lack of information in teaching. This has caused many scholars to fail to master the essentials of learning. In teaching, while helping students master basic knowledge, it is necessary to focus on cultivating students with a certain comprehensive quality, so that students can improve their comprehensive quality through learning, and have a wealth of knowledge, which will help students in future study and life.

\section{Oboe playing skills}

\subsection{Breath}

No matter what kind of woodwind instrument, the principle of pronunciation is the same, that is, the player controls the reed with his lips, and gives a certain pressure to make the instrument vibrate to make a sound. For the performance of the oboe, the good and bad playing skills are determined by breathing. Because the whistle of the oboe is narrow and the amount of air passing is relatively small, it is very important to breathe correctly. Generally, abdominal or chest-abdominal styles are used during performance, but some students use chest style to perform. Although this breathing method can also play with sufficient breath, the sound is relatively narrow and sullen.

\subsection{Lips}

The oboe uses a double-envelope shape, that is, when the windman is playing, the correct mouth shape is that the upper and lower teeth need to be separated. The two lips are covered with teeth as a cushion. The lower bala is flat. Put the reed between the lips. The strength of the reed is appropriate. The lips need to maintain a certain elasticity ${ }^{[1]}$. When playing, it is usually emphasized that there is no reed, that is, the length of the tip of the whistle into the lips should be suitable. The advantage of this is that the vibration of the reed is completely within the control range of the lips. The softer the vibration, the softer the tone.

\subsection{Fingering}

The finger movement is mainly controlled by the palm muscles. The finger needs to be raised to the correct height from the hole. It should be performed by relaxing the palm muscles. If you contract the muscles hard to keep the fingers straight, this will cause a certain burden on the back muscles that are not strong enough. When the finger moves up and down continuously, the distance of the finger from the hole is achieved by relaxing the back muscles of the hand and contracting naturally. In this way, the wrist and finger joints caused by excessive contraction of the back muscles when the finger is lifted can be avoided, and the finger is also flexible and relaxed.

Copyright (C) 2020 Yang Zhang

doi: $10.18282 / 1-$ e.v9i4.1743

This is an open-access article distributed under the terms of the Creative Commons Attribution Non-Commercial License (http://creativecommons.org/licenses/by-nc/4.0/), which permits unrestricted non-commercial use, distribution, and reproduction in any medium, provided the original work is properly cited.

Colleges and Universities [J].Higher Education Forum, (2): 8.

[4] Decision of the Central Committee of the Communist Party of China on Several Major Issues Concerning Upholding and Improving the Socialist System with Chinese Characteristics and Promoting the Modernization of the National Governance System and Governance Capacity[N]. People's Daily, 2019-11-5; (1). 